\title{
PRINCÍPIOS CONSTITUCIONAIS E DIREITO DO CONSUMIDOR FRENTE A COMERCIALIZAÇÃO DE BEBIDAS ÀLCÓOLICAS ${ }^{1}$
}

CONSTITUTIONAL PRINCIPLES AND CONSUMER RIGHT IN CONNECTION WITH THE

MARKETING OF ALCOHOLIC BEVERAGES

Felipe Amaral de CARVALHO ${ }^{2}$

ISSUE DOI: $10.21207 / 2675-0104.2018 .776$

\begin{abstract}
RESUMO
O presente trabalho tem como objetivo a análise dos princípios constitucionais com aspecto no direito do consumidor em relação a forma e a publicidade na comercialização da bebida alcóolica de teor alcoólico abaixo de 13 graus Gay-Lussac, tendo em vista a omissão da Lei n. 9.294/96 em desconformidade com o artigo $220, \S 4^{\circ}$ da Constituição Federal. Sabe-se que o consumo de bebida no Brasil vem crescendo ano a ano. Dessa forma, discute-se que a disseminação desse produto através da propaganda deve ser limitada pelos bons preceitos de proteção ao consumidor.
\end{abstract}

Palavras-chave: Princípios constitucionais. Proteção ao consumidor. Legislação.

\section{ABSTRACT}

The present paper has the objective of analyzing the constitutional principles with aspect in the consumer's right regarding form and advertising in the commercialization of the alcoholic beverage of alcohol content below 13 degrees Gay-Lussac, due to the omission of Law no. 9,294 / 96 in violation of article 220, $\$ 4$ of the Federal Constitution. It is known that beverage consumption in Brazil has been growing year by year. Thus, it is argued that the dissemination of this product through advertising should be limited by the good precepts of consumer protection.

\footnotetext{
${ }^{1} \mathrm{O}$ presente artigo sintetiza a monografia de conclusão da pesquisa, realizada para o Programa Interno de Bolsas de Iniciação Científica (PIBIC 2017-2018) da Faculdade de Direito de Franca (FDF), Franca/SP.

${ }^{2}$ Discente da Faculdade de Direito de Franca (FDF), Franca/SP. Bolsista do Programa Interno de Bolsas de Iniciação Científica (PIBIC 2017-2018).
} 
Keywords: Constitutional principles. Consumer protection. Legislation.

\section{INTRODUÇÃO}

O consumismo que cresce exorbitantemente, na chamada era pós moderna, movido por uma revolução tecnológica onde os meios de comunicação dos mais diversificados transmitem um alto teor informativo publicitário, passando a ser, não raramente, um fortíssimo instrumento de influência comportamental.

A publicidade é uma forma eficaz de convalidar as relações econômicas e garantir resultados positivos aos empreendimentos. Contudo, o alvo para atingir essa meta é justamente alcançar o consumidor que se encontra como destinatário final do produto. Este que, em muitas situações, não detém meios de se proteger, dependerá do Estado, para garantir os seus direitos como pessoa humana e até mesmo para exercer o seu direito à informação e à liberdade de escolha.

Sabe-se que o consumo de bebida no Brasil vem crescendo ano a ano no Brasil e tem causado prejuízos à sociedade. Contudo, discute-se se a disseminação desse tipo produto, através da publicidade e propaganda, deve ser filtrada pelos preceitos constitucionais de proteção ao consumidor. Exposto isso, analisa-se sobre a situação das relações de consumo frente aos meios de publicidade que envolve o comercio de bebidas alcoólicas, a respeito da efetivação desses direitos e garantias fundamentais, que, se ausentes, causam desequilíbrio e desrespeito ao consumidor.

\section{PRINCÍPIOS DO DIREITO E PRINCÍPIOS CONSTITUCIONAIS.}

Os princípios são uma base sobre o qual todo o ordenamento jurídico está colocado. Eles oferecem guarida e validade as demais normas e preceitos do Direito.

Nesse sentido, reitera Canotilho que os "princípios possuem uma função normogenética e uma função sistémica: são os fundamentos das 
normas jurídicas e têm uma idoneidade irradiante que lhes permite "ligar" ou cimentar todo o sistema" 3

No ordenamento eles possuem uma função explicadora e justificadora em relação as regras. Sintetizam uma grande quantidade de informação, conferindo unidade e ordenação ao sistema jurídico.

\subsection{OS PRINCÍPIOS NA CONSTITUIÇÃO BRASILEIRA DE 1988 E SUA INCIDÊNCIA NO CÓDIGO DO CONSUMIDOR.}

A Constituição é considerada a lei fundamental do Estado brasileiro. Percebe-se, portanto, como fica a importância dos princípios constitucionais em face do ordenamento jurídico, já que estes orientam, condicionam e esclarecem a interpretação das normas em geral. Então, os princípios constitucionais possuem características estruturais do Estado brasileiro que compõe os pilares de toda uma diretriz interpretativa que visa nortear os entendimentos sobre a aplicação de normas e preceitos.

Tendo em vista a incidência dos princípios Constitucionais como norteadores de todo o sistema jurídico, faz-se necessário consignar que o Código de Defesa do Consumidor, que é norma infraconstitucional, segue a aplicação dos princípios já consagrados.

Diante da proposta do tema a ser discutido, vale destacar que alguns princípios se destacam pela importância quando trata a respeito aos direitos e deveres, pois, no caso, é indiscutível o teor da valorização de ideal em relação à dignidade da pessoa humana, que constitui um dos principais pilares do estado Constitucional.

\subsection{FUNÇÕES DO PRINCÍPIO DA DIGNIDADE HUMANA.}

Como dito, Soares ${ }^{4}$, importante destacar que um dos maiores pilares da Constituição Federal está amparado na valorização dos direito humanos, assim, o princípio da dignidade da pessoa humana foi elevado ao patamar de fundamento do Estado brasileiro (art. $1^{\circ}$, III), integrando a categoria dos princípios fundamentais do Título I da Carta Magna.

\footnotetext{
${ }^{3}$ CANOTILHO, J.J Gomes. Direito Constitucional e teoria da constituição. $3^{\text {a }}$ ed. Lisboa: Livraria Almedina, ano 2000.

${ }^{4}$ SOARES, Ricardo Maurício Freire. O Princípio Constitucional da Dignidade da Pessoa Humana. $1^{\text {a }}$ ed. Saraiva: São Paulo, 2010. P. 135
} 
Nesse sentido, é dito que as normas da constituição precisam ser interpretadas à luz desse princípio, pois, assim, ele confere coerência substancial e unidade material entre tantas possibilidades de sentido de certos textos normativos.

Diante disso e, por isso, a tarefa dos órgãos estatais é, justamente, conferir a proteção da dignidade a todos os cidadãos, independentemente de qualquer acepção, assegurando sua efetividade através de medidas imperativas e positivas.

\section{PRINCÍPIOS QUE NORTEIAM AS RELAÇÕES DE CONSUMO, O DIREITO À INFORMAÇÃO E A QUESTÃO DA PUBLICIDADE.}

Como visto, o Código de Defesa do Consumidor foi criado com base nos princípios que inspiraram a Constituição Federal, sendo uma lei que valoriza principalmente a pessoa humana.

Porquanto, no caso em tela, priorizar o direito à informação é um meio que comprovadamente se mostra necessário. Nesse sentido, considerando os meios de comunicação que a cada dia oferecem mais e mais recursos para divulgação e venda de produtos e serviços, é notório que para algumas atividades comerciais deve haver uma limitação da livre iniciativa em favor da dignidade da pessoa humana.

Nesse sentido, pelo art. $4^{\circ}$, inciso III, do Código de Defesa do Consumidor, verifica-se que a intenção do legislador não é a supremacia exagerada do consumidor, mas sim o equilíbrio na relação consumerista. Os direitos de ambos devem estar resguardados, bem como valorizados e é, nesse sentido, que se discute o tema da liberdade de comercialização da bebida alcoólica com concentração alcoólica abaixo dos 13 graus.

Não obstante, Nesse mesmo diapasão, o Código do Consumidor, em seu art. $6^{\circ}$, inciso III, garante ao consumidor "A informação adequada e clara sobre diferentes produtos e serviços [...] bem como sobre os riscos que apresentem;"

Ada Pelegrini ${ }^{5}$, em comento a tal dispositivo disserta sobre o dever do fornecedor em informar bem o público consumidor sobre todas as características importantes dos produtos ou serviços, para que o

\footnotetext{
5 GRINOVER, ADA PELLEGREINI. ET AL.: Código brasileiro de Defesa do consumidor: Comentados pelos autores do ante projeto. $11^{\mathrm{a}}$ ed. Forence: Rio de Janeiro, 2017. Pág. 150.
} 
consumidor possa adquiri-los tendo a absoluta consciência do que poderá aguardar deles.

Com base nisto, o fornecedor tem a obrigação de trazer todas as informações acerca do produto de forma que o consumidor fique inteiramente consciente do que está adquirindo. Dessa forma, a informação jamais pode faltar com a verdade, quer por omissão, quer por afirmação. O informante não pode manipular frases, sons e imagens para que, de maneira confusa, iluda o destinatário da informação.

Considerando todo o exposto, em se tratando de produtos que podem causar danos e riscos ao consumidor, como a bebida alcoólica em qualquer nível de concentração de álcool, tendo em vista que a mensagem publicitária, atualmente, vai além de mera informação e passa a ser, não raras vezes, um forte instrumento de influência comportamental, discutese a necessidade dos limites constitucionais e legais, com a finalidade de resguardar o consumidor em sua dignidade e direito, em detrimento com a livre iniciativa e liberdade dos fornecedores.

Obviamente, que, além de outros princípios, o carácter protetivo em relação a dignidade humana do consumidor é alicerce da norma e inquestionável à luz do código consumerista, o qual, conforme consta, preocupa-se com a saúde, a segurança e qualidade de vida do consumidor, bem como uma forma de mantê-lo educado quanto a todos os riscos do produto ofertado no mercado.

Nesse contexto, o Código de Defesa Consumidor desenvolveu mecanismo para a proteção do consumidor e, nesse sentido, vedou, no seu artigo 36, as mensagens subliminares, possibilitando o consumidor identificar a publicidade de forma fácil e imediata.

De outra forma, o artigo 31 c.c o art. $37 \S \S 1^{\circ}$ e $3^{\circ}$ trata do princípio da veracidade os quais garantem a proteção contra todo o tipo de publicidade enganosa ou abusiva, quer seja por ação ou omissão.

Conclui-se, portanto, que os dispositivos visam proteger valores fundamentais do consumidor, incluindo aqueles relacionados à segurança, à saúde e bem-estar, bem como daqueles inerente à proteção da criança $\mathrm{e}$ do meio ambiente.

\section{A COMERCIALIZAÇÃO DE BEBIDA ALCOÓLICA.}

No Brasil a bebida é comercializada de forma lícita para pessoas maiores de 18 anos e bastante difundida, faz parte da cultura do brasileiro. 
Ao contrário de outras drogas, o álcool existe como um meio de intercâmbio social e de comunicação.

É nesse cenário que se discute acerca da publicidade de bebidas alcoólicas, pois, na verdade, ela, de certa forma, difunde e constrói conceitos de moral, costume e de comportamento social. Difundindo seus próprios interesses, que é a disseminação do produto no mercado, de forma a destacar apenas certos efeitos do uso, sem promove, o que seria o ideal, o consumo controlado e regrado dessa substância.

\subsection{O CONAR - CONSELHO NACIONAL DE AUTORREGULAMENTAÇÃO PUBLICITÁRIA}

Nesse contex to está inserido o Conselho de Autorregulamentação Publicitária - CONAR, que é um órgão regulador não governamental. Este que tem por objetivo, através do Código de Autorregulamentação Publicitária, a regulamentação das normas éticas aplicáveis à publicidade e propaganda.

Este código define alguns preceitos básicos que determinam a ética publicitária, a vista de que todo anúncio deve ser honesto e verdadeiro e respeitar as leis do país; deve ser preparado com o devido senso de responsabilidade social, evitando acentuar diferenciações sociais; deve ter presente a responsabilidade da cadeia de produção junto ao consumidor; deve respeitar o princípio da leal concorrência e deve respeitar a atividade publicitária e não desmerecer a confiança do público nos serviços que a publicidade presta. (CONAR, Código Brasileiro de Autorregulamentação Publicitária, 2017).

O Código de Autorregulamentação Publicitária constitui-se na única regra trata da limitação da publicidade de bebidas alcoólicas no Brasil. Dessa forma, apesar de toda a credibilidade e respeitabilidade do CONAR, suas decisão não tem efeito vinculativo, tão pouco, caráter coativo de norma legal. PUBLICITÁRIA. 
Ao observar os princípios gerais do Código Brasileiro de Autorregulamentação Publicitária ${ }^{6}$, nota-se que este se inspira veementemente na Constituição Federal de 1988, bem como no Código de Defesa do Consumidor, pois visa a proteção do consumidor e de sua dignidade, saúde e segurança.

Dessa forma, o Princípio da Respeitabilidade, estabelecido nos arts. 19 ao 21 do Código Brasileiro de Autorregulamentação Publicitária, estabelece, como prisma para as publicidades, o respeito à dignidade humana, à intimidade, ao interesse social, nesse sentido, nenhuma propaganda deve estimular qualquer tipo de discriminação racial, social, política, religiosa ou de nacionalidade. O princípio também proíbe o induzimento ao destinatário do anúncio à prática delituosa ou criminosas. Nota-se que este princípio está claramente em consonância com os princípios Constitucionais e de Defesa do Consumidor, discutidos em itens acima na pesquisa.

Com vista nisso, acerca da publicidade de bebidas alcoólicas de teor alcoólico abaixo dos 13 graus Gay-Lussac, o ANEXO "A", do Código, estabelece que é vedado o apelo imperativo para o consumo do produto ou que em algum anúncio sugira o consumo exagerado do mesmo. Dessa forma, consagra-se o princípio da responsabilidade social, o qual, doutra feita, também proíbe os eventuais apelos à sensualidade nos anúncios, de forma que os modelos publicitários jamais devem figurar como objetos sexuais.

Essa regra expressa a valorização da mulher, que, por vários anos, sofreu com os abusos da publicidade, no sentido de utilizar a imagem feminina como um objeto sexual. Essas propagandas foram utilizadas com o objetivo de atrair o público masculino, vez que eram majoritário para o consumo da bebida alcoólica.

Entretanto, o que se pode notar nos últimos anos é que esse modelo de publicidade tem sido substituído por outros. Os tempos mudaram, as mulheres entraram em uma luta feroz contra a sociedade machista e conseguido inverter alguns valores. Com tudo isso, a publicidade e o meio midiático, não se quedou alheio. Logo trataram de "atualizar" o seu discurso, a fim de não perder a credibilidade no mercado.

Outra regra muito importante estabelecida no Código Brasileiro de Autorregulamentação Publicitária, é a proteção da criança e do adolescente, os quais não podem, em hipótese alguma, serem os

6 CONAR. Código Brasileiro de Autorregulamentação Publicitária - Código e Anexos. 2017. Disponível em http://www.conar.org.br/codigo/codigo.php. Acesso 04 de janeiro de 2018. 
destinatários finais do anúncio. Com isto, todo o artifício publicitário que chame a atenção do menor, são motivos para a sua restrição.

Apesar do conteúdo do Código de Autorregulamentação Publicitária, bem como a credibilidade do Conar, para muitos, a sua eficiência é questionada. No artigo científico realizado pelo Departamento de Psiquiatria e Psicologia Médica da Universidade Federal de São Paulo, afirma-se que estudos realizados em diferentes países demonstram que o controle de conteúdo e a frequência da publicidade para o público jovem, acarretam interpretações muito subjetivas e a Autorregulamentação acaba falhando no seu objetivo de proteger esse público mais vulnerável às propagandas de bebidas alcoólicas pela percepção de similaridade entre a propaganda e situações de vida da maioria dos adolescentes.

Além do mais, o artigo comenta que a Autorregulamentação não evita o direcionamento das propagandas ao público infantil, e tão pouco o consumo exagerado do produto. Reafirma que no fim, as empresas e as agências de publicidade acabam realizando os seus próprios desígnios, o qual é aumentar a venda do seu produto e angariar mais espaço no mercado.

\subsection{ASPECTOS DA LEI FEDERAL N. 9.294/96.}

A Lei federal $n^{\circ}$ 9.294/96 foi editada para o cumprimento do dispositivo do $\S 4^{\circ}$ do artigo 220 da Constituição Federal da República, que visa a restrição da propaganda de determinados produtos, principalmente, de bebidas alcoólicas, como sendo nocivos à saúde. A lei considera regulamentar a as propagandas dos produtos sujeitos às restrições e condições com previsão na Constituição Federal. Contudo, considerou bebidas alcoólicas, para efeitos da lei, aquelas com teor alcoólico superior a 13 graus Gay Lussac. Desta feita, de acordo com a lei, a publicidade de cervejas, vinhos, ices e etc., não estão incluídas.

Esse tema tem sido objeto de discussão no Congresso Nacional, onde foram propostos alguns projetos de Lei que visam mudar o parágrafo único do art. $1^{\circ}$ da Lei, a fim de que sejam incluídas como bebidas alcoólicas aquelas superiores a 0,5 graus Gay Lussac. Um deles foi o projeto de Lei 7466/2017 proposto pelo deputado André Fufuca - PP/MA. ${ }^{7}$

\footnotetext{
7 BRASIL, Câmara dos Deputados Federal. Projeto de Lei $n^{\circ} 7466 / 2017$. Dispõe sobre a obrigatoriedade de inclusão de imagens nas embalagens de bebidas alcoólicas produzidas no âmbito do território nacional e dá outras providências. Disponível em: http://www.camara.gov.br/proposicoesWeb/fichadetramitacao?idProposicao=2130647
} 
O projeto dispõe sobre a obrigatoriedade de inclusão de imagens nas embalagens de bebidas alcoólicas que conscientizem o consumidor dos riscos dos produtos. Essas imagens correspondem a fotografias de veículos em colisão ou decorrentes de acidentes em que o motorista se encontrava sob efeito de álcool, conforme art. $1^{\circ}, \S 2^{\circ}$, do PL.

\title{
3.4 A JURISPRUDÊNCIA NOS TRIBUNAIS
}

Acerca do tema, a Procuradoria-Geral da República propôs Ação Direta de Inconstitucionalidade Por Omissão $n^{\circ}$ 22/STF, onde foi discutido sobre possibilidade de mora legislativa quanto à regulamentação do art. $220, \S 4^{\circ}$, da Constituição, devido a extensão da Lei $9.294 / 96$ não ser a todo o tipo de bebida alcoólica.

Por quanto, a Procuradoria-Geral requereu a declaração de tal mora legislativa, para que os efeitos da norma 9.264/96 fosse estendido a todas as bebidas alcoólicas independentemente do seu teor de álcool, até que fosse superada a lacuna legislativa".

Com base nisto, na assentada de 22 de abril de 2015, tendo como ministra Relatora a excelentíssima Cármen Lúcia, o Plenário da Suprema Corte concluiu:

\begin{abstract}
AÇÃO DIRETA DE INCONSTITUCIONALIDADE POR OMISSÃO. REGULAMENTAÇÃO DE PROPAGANDA DE BEBIDAS DE TEOR ALCOÓLICO INFERIOR A TREZE GRAUS GAY LUSSAC ( $\left.13^{\circ} \mathrm{GL}\right)$. AUSÊNCIA DE OMISSÃO. ATUAÇÃO DO PODER LEGISLATIVO. ART. $2^{\circ}$ DA CONSTITUIÇÃO DA REPÚBLICA. IMPOSSIBILIDADE DE ATUAR O SUPREMO TRIBUNAL FEDERAL COMO LEGISLADOR POSITIVO, SUBSTITUINDO-SE AO PODER LEGISLATIVO NA DEFINIÇÃO DE CRITÉRIOS ADOTADOS NA APROVAÇÃO DAS NORMAS DE PROPAGANDA DE BEBIDAS ALCOÓLICAS: PRECEDENTES. AÇÃO JULGADA IMPROCEDENTE. DECISÃO COM EFEITOS VINCUANTES. (STF, 2015, on-line)
\end{abstract}

Assim, decidiu o supremo que a questão está afeta ao poder legislativo e que este, outrora, já havia debatido exaustivamente essa questão nas casas legislativas, em sede do projeto Lei n. 4556/1989, o qual tramitou durante 7 (sete) anos e deu origem à Lei 9.294/1996. 


\section{5}

\section{CONSIDERAÇÕES FINAIS.}

A pesquisa trata de comandos constitucionais, os quais são norteados pelo princípio da dignidade da pessoa humana, considerando, ainda, a garantia fundamental do dever do Estado para promover a defesa do consumidor e, em consequência, amoldado à comunicação social, surge a obrigação de regulamentar as propagandas de determinados produtos, dentre eles a própria propaganda de bebida alcoólica.

Portanto, foram analisados os princípios do direito e os princípios constitucionais, considerando os direitos e as garantias individuais, frente as relações comerciais que, envolvam publicidade de bebidas alcoólicas, especificamente, com teor alcoólico abaixo de 13 Graus Gay-Lussac, uma vez que esta carece de regulamentação específica, mesmo após a Constituição Federal, em seu art. 220, $\S 4^{\circ}$, da Constituição Federal de 1988, preceituar, expressamente, tratando da restrição de publicidade para determinados produtos, em especial a bebida alcoólica.

Assim considerando, o intuito é promover a discussão em face dos efeitos nocivo do álcool e a falta de informação ao consumidor que fica exposto a publicidade que possui o aval da lei para veicular o produto através dos vários meios de comunicação, sem qualquer restrição. Aliás, diante do aparato de normas e princípios que compõe o sistema jurídico, foi traçado um paralelo com relação a essa questão, debatido no âmbito dos estudos das ciências sociais de forma multidisciplinar.

Desta feita, o cerne da questão está na permissão da abusiva publicidade das bebidas alcoólicas que vem ocorrendo por nítida omissão da norma. Fato que, como notoriamente demonstrado ao logo do presente trabalho, fere os princípios norteadores do direito e da Constituição.

Sendo o caso de garantir a proteção do consumidor, o Estado não deve ficar compassivo diante da falta de regulamentação para a publicidade de bebidas alcoólica, seja de baixo teor ou não. No entanto, o fato é que não há restrição verdadeiramente efetiva.

Não obstante, como visto, o que realmente tem ocorrido no cenário da comercialização de bebida alcoólica, é justamente um desequilíbrio dessa relação, pois o fornecedor tem se beneficiado da omissão da lei, utilizado os meios de propaganda para estimular o consumo e a venda da bebida alcoólica de baixo teor, sob o argumento da livreiniciativa e a liberdade de expressão dos meios de comunicação, contrariando, enfaticamente, o expositivo Constitucional. 
Uma vez que Estado brasileiro é um Estado Democrático de Direito, regido pela valorização da dignidade da pessoa humana, deve firmar-se em não somente em proteger o seu cidadão de todo abuso que ataque ou fira tal princípio, mas também agir positivamente para garantir e efetivação do mesmo, por meio de todos os mecanismos que lhe sejam atribuídos.

Conclui-se, portanto, com base em todos os argumentos aqui expostos que, a vista do comando constitucional previsto no artigo 220 , § $4^{\circ}$, no que se refere às bebidas com teor alcoólico inferior a 13 graus Gay Lussac, permanece, até a presente data, sem qualquer regulamentação efetiva, desde a promulgação da Constituição Federal. Porquanto, a única forma de tornar a comercialização de bebidas alcoólicas, seja com baixo teor ou não, restrita em todo o Brasil, será por meio de regulamentação de lei específica, seja para criar ou alterar a Lei Federal nº 9.294/96.

\section{REFERÊNCIAS BIBLIOGRÁFICAS}

ACSELRAD, G.; KARAM, M.L.; DAVID, H.M.S.L; ALARCON, S. Consumo de bebidas alcoólicas no Brasil. Faculdade Latinoamericana de Ciências Sociais, 2012. Pág. 63-64.

ALMEIDA, João Batista de. Manual de Direito do consumidor. 6ª ed. São Paulo: Saraiva, 2015. ISBN: 9788502616837 . Acesso em 25 de janeiro de 2018.

AMARAL, Luiz Otávio de Oliveira: Teoria Geral do consumidor. $1^{\text {a }}$ ed. Revista dos tribunais, São Paulo. 2010.

ANDRADE, Arthur Guerra; ANTONY, James C; SILVEIRA, Camila Magalhães. Álcool e suas consequências. $1^{\text {a }}$ ed. Barueri: Manole. 2009.

BARBOSA. Fernanda Nunes. Informação: direitos e dever nas relações de consumo. Revista dos Tribunais, São Paulo. Disponível em: http://bdjur.stj.jus.br/dspace/handle/2011/21585. Acesso em 04 de julho de 2018.

BARCELlOS, Ana Paula de. Curso de Direito Constitucional/Ana Paula de Barcellos. Rio de Janeiro: Forense, 2018. ISBN 9788530980115. Disponível em: https://forumdeconcursos.com/wpcontent/uploads/wpforo/attachments/2/1751-Curso-de-Direito-Constitucional-2018-Ana-Paula-deBarcellos.pdf. Acesso em 27 de fevereiro de 2018.

BRASIL, Supremo Tribunal Federal. Ação direita de inconstitucionalidade por omissão n ${ }^{\circ}$ 22/DF Distrito Federal. Relatora Ministra Cármen Lúcia. Pesquisa de Jurisprudência. Acórdão 22/11/2015. Disponível em:

http://www.stf.jus.br/portal/jurisprudencia/listarJurisprudencia.asp?s1=\%2822\%2ENUME $\% 2 \mathrm{E}+\mathrm{OU}+$ $22 \% 2 \mathrm{EACMS} \% 2 \mathrm{E} \% 29+\% 28 \% 28 \mathrm{C} \% \mathrm{C} 1 \mathrm{RMEN}+\mathrm{L} \% \mathrm{DACIA} \% 29 \% 2 \mathrm{ENORL} \% 2 \mathrm{E}+\mathrm{OU}+\% 28 \mathrm{C} \% \mathrm{C} 1 \mathrm{R}$ MEN+L\%DACIA \%29\%2ENORV\%2E+OU+\%28C\%C1RMEN+L\%DACIA\%29\%2ENORA\%2E+ 
OU+\%28C\%C1RMEN+L\%DACIA\%29\%2EACMS\%2E\%29\%28\%40JULG+\%3E\%3D+20130217

$\% 29 \&$ base=baseAcordaos\&url=http://tinyurl.com/y8lrv3zv. Acesso em 09 de maio de 2018.

Lei $\mathrm{n}^{\circ} 9.294$ de 15 de julho de 1996. Dispõe sobre as restrições ao uso e à propaganda de produtos fumígeros, bebidas alcoólicas, medicamentos, terapias e defensivos agrícolas, nos termos do $\S 4^{\circ}$ do art. 220 da Constituição Federal. Disponível em:

http://www.planalto.gov.br/ccivil_03/LEIS/L9294.htm. Acesso em 04 de março de 2018.

. Lei $\mathrm{n}^{\mathrm{o}} 11.705$ de 19 de junho de 2008. Altera a Lei no 9.503, de 23 de setembro de 1997, que 'institui o Código de Trânsito Brasileiro', e a Lei no 9.294, de 15 de julho de 1996, que dispõe sobre as restrições ao uso e à propaganda de produtos fumígeros, bebidas alcoólicas, medicamentos, terapias e defensivos agrícolas, nos termos do § 4o do art. 220 da Constituição Federal, para inibir o consumo de bebida alcoólica por condutor de veículo automotor, e dá outras providências. Disponível em: http://www.planalto.gov.br/ccivil_03/_Ato2007-

2010/2008/Lei/L11705.htm. Acesso em 04 de março de 2018.

. Lei $\mathrm{n}^{\mathrm{a}} 8.078$ de 11 de setembro de 1990. Dispõe sobre a proteção do consumidor e dá outras providências. Disponível em: http://www.planalto.gov.br/ccivil_03/LEIS/L8078.htm. Acesso em 04 de março de 2018.

Constituição (1988). Constituição da República Federativa do Brasil. Brasília, DF: Senado Federal: Centro Gráfico, 1988. 292 p. Acesso em 03 de dezembro de 2017.

Superior Tribunal de Justiça. Pesquisa de Jurisprudência. STJ. Recurso Especial $n^{\circ}$ 1261943 SP. Recorrente: Companhia Muller de Bebidas. Recorrido: Odair de Souza - Espólio. Rel. Ministro Massami Uyeda. $3^{a}$ Turma. Data de Julgamento: 22/11/2011. Disponível em: https://ww2.stj.jus.br/jurisprudencia/externo/informativo/?acao=pesquisar\&processo=1261943+SP+ \&operador $=\mathrm{e} \& \mathrm{~b}=\mathrm{INFJ} \&$ thesaurus=JURIDICO. Acesso em 23 de dezembro de 2017.

. Câmara dos Deputados Federal. Projeto de Lei n ${ }^{\circ} 7466 / 2017$. Dispõe sobre a obrigatoriedade de inclusão de imagens nas embalagens de bebidas alcoólicas produzidas no âmbito do território nacional e dá outras providências. Disponível em:

http://www.camara.gov.br/proposicoesWeb/fichadetramitacao?idProposicao=2130647. Acesso em 05 de janeiro de 2018.

Senado Federal. Projeto de Lei na 169, de 2011. Modifica a Lei n ${ }^{\circ} 11.705$, de 19 de junho de 2008, que "altera a Lei $n^{\circ} 9.503$, de 23 de setembro de 1997, que `institui o Código de Trânsito Brasileiro', e a Lei n ${ }^{\circ}$ 9.294, de 15 de julho de 1996, que 'dispõe sobre as restrições ao uso e à propaganda de produtos fumígeros, bebidas alcoólicas, medicamentos, terapias e defensivos agrícolas, nos termos do $\S 4^{\circ}$ do art. 220 da Constituição Federal', para inibir o consumo de bebida alcoólica por condutor de veículo automotor, e dá outras providências", no sentido de vedar a venda de bebidas alcoólicas nos estabelecimentos e nas condições que especifica. Disponível em: https://www25.senado.leg.br/web/atividade/materias/-/materia/99933. Acesso em 04 de janeiro de 2018.

CANOTILHO, J.J Gomes. Direito Constitucional e teoria da constituição. $3^{\mathrm{a}}$ ed. Lisboa: Livraria Almedina, ano 2000.

CARVALHO, Luiz Gustavo Castanho de. Direito de informação e liberdade de expressão. $1^{\mathrm{a}}$ ed. Rio de Janeiro: Renovar, 1999. 
CONAR. Código Brasileiro de Autorregulamentação Publicitária. 2017. Disponível em: http://www.conar.org.br/. Acesso em 04 de janeiro de 2018.

FARIA, R.; VENDRAME, A.; SILVA, R.; PINSKY, I. (2011). Propaganda de álcool e associação ao consumo de cerveja por adolescentes. Rev. Saúde Pública, pág. 442-447. Disponível em: http://www.scielo.br/pdf/rsp/v45n3/1827.pdf. Acesso em 23 de dezembro de 2017.

FILHO PENTEADO, N.S.; Direitos Humanos. $2^{\mathrm{a}}$ ed., 2011. São Paulo, Saraiva.

FILHO WUNSCH, Victor. Consumo de Bebidas Alcoólicas e risco de câncer. Rev USP, São Paulo, $n^{\circ}$ 96. P. 37-46, Dezembro/Fevereiro 2012-2013.

GARCIA, Leonardo de Medeiros. O princípio da informação na pós-modernidade: Direito fundamental do consumidor para o equilíbrio nas relações de consumo. Revista Jurídica, São Paulo, v 64, n. 464, p 29-54, junh. 2016. Disponível em:

http://bdjur.stj.jus.br/jspui/handle/2011/103593. Acesso em 05 de março de 2018.

GRINOVER, ADA PELLEGREINI. ET AL.: Código brasileiro de Defesa do consumidor:

Comentados pelos autores do ante projeto. $11^{\mathrm{a}}$ ed. Forence: Rio de Janeiro, 2017.

JANCZESKI, Célio Armando. Constituição Federal Comentada1ª ed. Juruá: Curitiba, 2012.

LÔBO, Paulo Luiz Netto. Teoria Geral das Obrigações. $1^{\text {a }}$ ed. São Paulo: Saraiva, 2005.

MACHADO, C. CHINELLATO, S. J. Código Civil interpretado: artigo por artigo, parágrafo por parágrafo. $9^{a}$ ed. São Paulo: Manole, 2016.

MARQUES, Claudia Lima; BENHAMIM, Antonio Herman V.; MIRAGEM, Bruno. Comentários ao Código de Defesa do Consumidor; $5^{a}$ ed. rev, atual e ampl.. São Paulo: Revista dos Tribunais, 2016

MENDES, G.F.; SARLET, I.W.; STRECK, L.L.; LEONCY, L.F.; CANOTILHO, J.J.G. Comentários à Constituição do Brasil. $1^{\text {a }}$ ed., 2013. São Paulo, Saraiva. ISBN 9788502212633. Acesso em 23 de dezembro de 2017.

MORAES, Alexandre de. Direito Constitucional. 17 ed. São Paulo, Atlas. 2005.

NUNES, RIZZATO: Curso de Direito do Consumidor. 10ª ed. São Paulo: Saraiva, 2018.

PAULO, V.; ALEXANDRINO. Direito Constitucional Descomplicado. 17 ed. rev e atual. 2018. São Paulo, Método.

PINSKY, Ilana. Publicidade de bebidas alcoólicas e os jovens. São Paulo, Câmara Brasileira do livro, 2009. ISBN 9788572444293. Acesso em 23 de dezembro de 2017.

SARLET, I.W.; MARIONI, L. G.; MITIDIERO, D.; Curso de direito constitucional. $6^{\mathrm{a}}$ ed. Saraiva: São Paulo, 2017.

SILVA, José Afonso da. Curso de Direito Constitucional Positivo. 26ª ed. São Paulo, Malheiros, 2005. 
SOARES, Ricardo Maurício Freire. O Princípio Constitucional da Dignidade da Pessoa Humana. $1^{\text {a }}$ ed. Saraiva: São Paulo, 2010. 